(B) $V=100 \mathrm{cc}, T=200 \mathrm{sec}$.

\begin{tabular}{|c|c|c|c|c|c|c|c|c|c|c|}
\hline \multirow{2}{*}{$\begin{array}{l}\text { Exp. } \\
\text { No. }\end{array}$} & \multirow{2}{*}{$\begin{array}{c}\text { Temp. } \\
\left({ }^{\circ} \mathrm{C}\right)\end{array}$} & \multicolumn{8}{|c|}{ Readings of the chart, $\mathrm{C}_{2} \mathrm{H}_{2}(\%)$} & \multirow{2}{*}{$\begin{array}{c}\text { mean } \\
\mathrm{C}_{2} \mathrm{H}_{2}(\%)\end{array}$} \\
\hline & & 1 & 2 & 3 & 4 & 5 & 6 & 7 & 8 & \\
\hline 4 & 26 & 0.050 & 0.05 & .05 & 0.055 & 05 & .05 & .053 & .055 & 0.054 \\
\hline
\end{tabular}

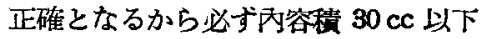
のボンブを用いなけれはならない。 たボンブと檢知管とを連結するために 用いるゴム管がゆるんていると試料ガ スの油れのため低、值が出る. その他 試料ガスの揆入方泆不は濃度表の請み

\section{4. 結論}

上述の上5に各種の精度試驗を行つた結果, 檢知管に よるアセチレン濃度の測定值は，その操作法海りがな ければ，贵用的に見て常に正しい結果を與えるととが制 つた.

检知管法はその棒造が甚だ簡單で，その操作が簡易て あるが故に，屡っその測定精度が劣るように解釋せられ 易いが，贯際々は检知管法は管內俓に對する補正，遙入 速度の均等化，溫度飞對する補正，濃度表の活用などの 改良によつて貫用的に十分に正確な測定値の得られるよ 5研究が行われたるのであるから，事望その精度は上 述のようК相當高いのである(5).

從つて池田氏の報告の如く(4)，檢知管を用いたてセチ レン濃度の測定に括いて甚だ不正確な值が得られたの は，恐らく检知管法の操作上の誤りに歸せらるべきでは ないかと考党る.例党ばガス探取器として內签棈 $100 \mathrm{cc}$ のポンプを用いると，V=10ce の試料ガスの䢪入が不
万の相異などに誤りの原因があつたのではないかと考え られる. 向检知管に充填する检知潇の製法とついては從 前より全く枚りはなく，また检知劑は製造後十分に湜同 を行 万ために指摘せられたよらな擔體シリカゲル粒に對 する試䒚の收着の不均一は起ることはあり得ない。

これを慗するに檢知管による空氣中のアセチレン澧度 の測定值は種々の精度試羷を行つて檢討した結果, その 操作を俱りなく行えほ常に信賴し5る值が得られるとと が結論せられた。

向との䃑究は交部省科學的究費の援助によつた。 (昭和 27 年 4 月 5 日受理)

交 献

(1) 失木策, 武岡孝沿: 工化, 34,576（昭 6)

(2) L. Ilosvay von Nagy Ilosva : Ber., 32, 2697 (1899)

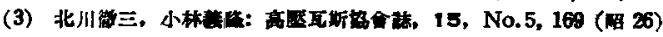

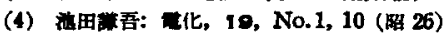

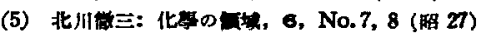

(6) R. Willstätter u. E. Maschmann : Ber., 53, 939 (1920)

(7) H. Arnold, E. Möllney u. F. Zimmermannn: Ber., 53, 1034 (1920)

\title{
自己平衡型自㗢温度調管器
}

\author{
吉田重藏 \\ (東芝マッタ（研究所） \\ Self-Balancing Wheatstone Bridge Type Thermostat \\ Juzo YOSHIDA \\ (Matsuda Research Laboratory, Tokyo-Shibaura Electric Co., Kawasaki) \\ relay. A very simple circuit of this type can \\ control the temperatures below $1300^{\circ} \mathrm{C}$ of $50 \mathrm{~W}$ \\ platinium furnaces within the accuracy of \\ $\pm 1.0^{\circ} \mathrm{C}$. \\ (Received Nov. 5, 1951)
}

For regulating the temperatures of very small electric furnaces, a self-balancing Wheatstone bridge type thermostat is devised. This unit is composed of four parts : a bridge, a vacuum tube amplifier, a discriminator and a

\section{1. 緒}

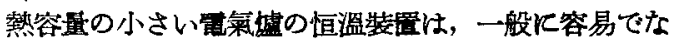
い. 筆者は Fig. 3 のよ5な極めて熱容量の小さな㛭に 自己平衡型自働溫度調節法を應用して見た。この方法は 電熱線として抵抗溫度係數の高い $\mathrm{Ni}, \mathrm{W}, \mathrm{Mo}, \mathrm{Pt}$ 等を用 い，それ自身を感溫抵抗としてホイトストンブリッジの 一邊に組込んだ形の自働溫度調節器で從來種々の提案(1)

がある.篚者の試みた回路は頗る簡單なるのであるが， 好結果を得たのて報告する.

\section{2. 使用回 路}

Fig. 1 は構成圖、Fig. 2 は Fig. 3 そ示した 50W 位

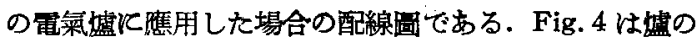
熱容量の小さい事を示すために揭げた㥀の自然泠却曲線 である. Fig. 1 の R, Q， R の固定抵抗は溫度係孉の 


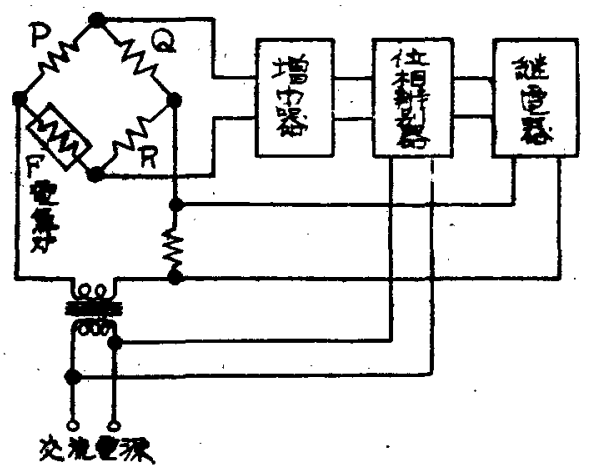

Fig. 1 模 成

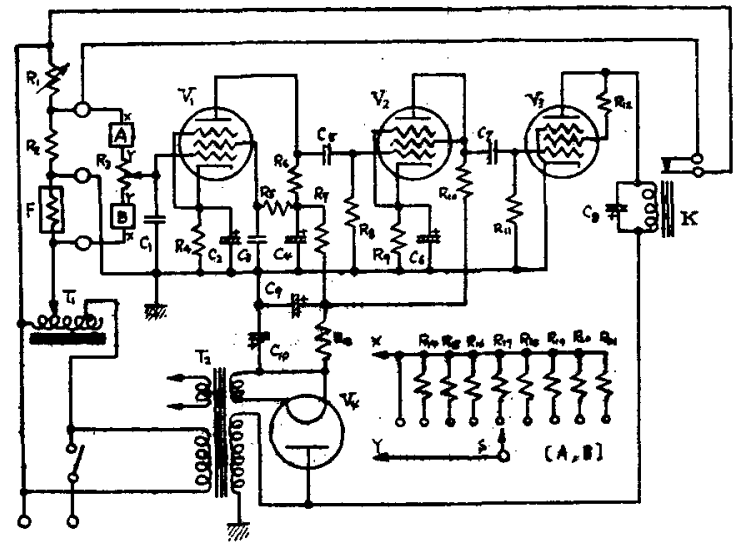

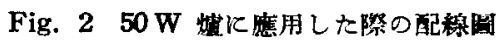
部品定数

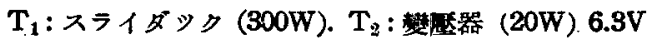
$-1 \mathrm{~A}, 5 \mathrm{~V}-0.5 \mathrm{~A}, 300 \mathrm{~V}-30 \mathrm{~mA}$. $\mathrm{V}_{1}, \mathrm{~V}_{2}: \mathrm{UZ}-6 \mathrm{C6}$. $\mathrm{V}_{3}$ :

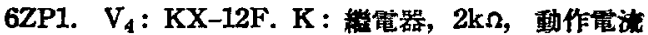

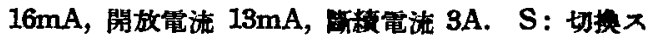
イッチ. F : 白金電氣溃 (50W) (Fig. 3). $R_{1}$ : 渭娌

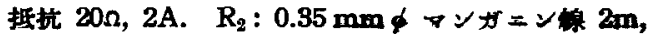

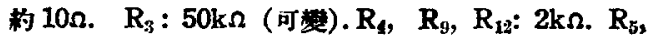
$R_{8}, R_{21}: 500 \mathrm{k} \Omega . R_{6}, R_{90}: 250 \mathrm{k} \Omega . R_{7}: 50 \mathrm{k} \Omega . R_{10}$, $R_{11}$ : 30k $\Omega$. $R_{15}, R_{15}: 10 \mathrm{k} \Omega$. $R_{14}: 5 \mathrm{k} \Omega . R_{16}: 20$ $\mathrm{k} \Omega ., R_{17}: 40 \mathrm{k} \Omega . \quad \mathrm{R}_{18}: 70 \mathrm{k} \Omega . \quad \mathrm{R}_{19}: 150 \mathrm{k} \Omega . \mathrm{C}_{1}$ : $0.002 \mu \mathrm{F} . \mathrm{C}_{2}, \mathrm{C}_{6}$ : 毾解 $20 \mu \mathrm{F}$, 60V. $\mathrm{C}_{3}, \mathrm{C}_{7}: 1 \mu \mathrm{F}$. $\mathrm{C}_{4}, \mathrm{C}_{9}, \mathrm{C}_{2 n}$ : 整藓 $8 \mu \mathrm{F}, 450 \mathrm{~V} . \mathrm{C}_{5}: 0.1 \mu \mathrm{F} . \mathrm{C}_{8}$ : 䉓解 $50 \mu \mathrm{F}$, $50 \mathrm{~V}$.

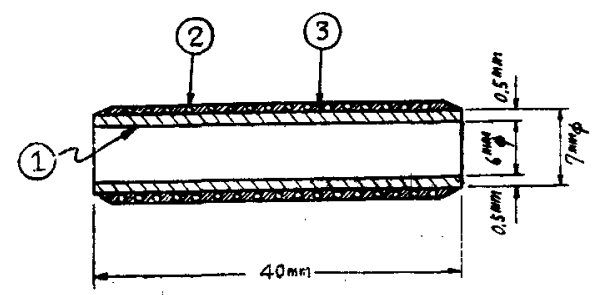

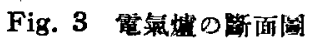

(1)薄肉 alundum 管

(2)白金糗 $0.2 \mathrm{~mm} \phi \times 50 \mathrm{~cm}$ (宝温的 $2 \Omega$ )

(2)素目䊀土 1 静+alundum 粉 3 部

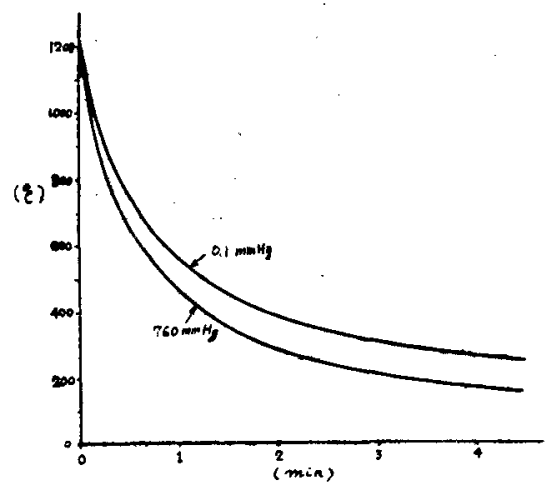

Fig. 4 Fig. 3 の電氣蛊の自然冷却曲線
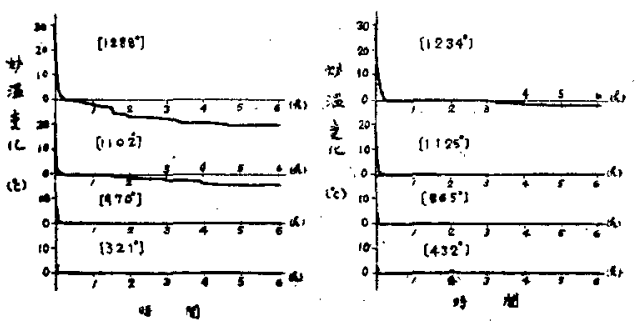

(a) (b)

Fig. 5 化

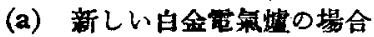

(b) その嘖を $1200^{\circ} \mathrm{C}$ 以下の種々の温度で䄪 4 ケ月 此用した倦

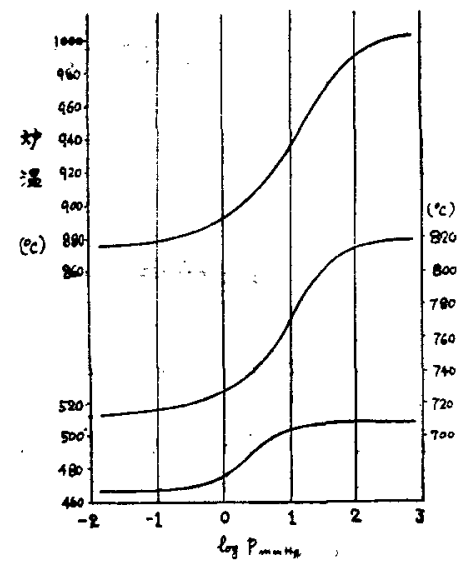

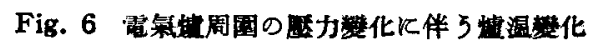

小さい事が必要でマンガニン等を使 $\mathrm{P}, \mathrm{Q}$ 郎ち Fig. 2 の A, B， R 等は高抵抗のため炭素 抵抗の方が便利である。炭素抵抗についての測定(2)によ

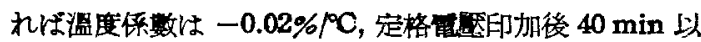
內の䢎抗值の變化は $10 \mathrm{~min}$ 以後には $0.04 \%, 20 \mathrm{~min}$

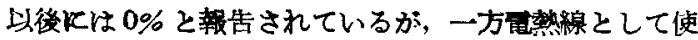
用する $\mathrm{Pt}, \mathrm{Ni}$ 等の抵抗溫度係数は $0.4 \% /{ }^{\circ} \mathrm{C}$ 位である

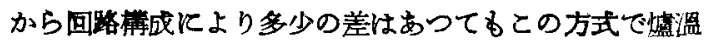
を音盢等化の $10 \%$ 以下に止める事は可能と思われる。 


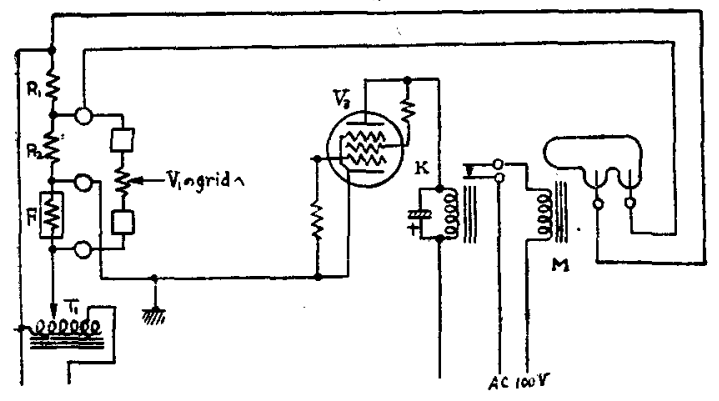

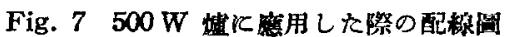

$\mathrm{T}_{1}$ スライダック $(1 \mathrm{~kW})$

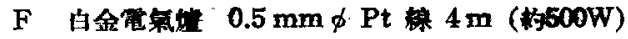

M 水銀電的的器

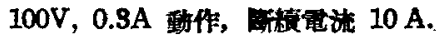

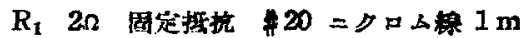

$R_{2} 2 \Omega$ 固定抵执 \#22 マンガニン楾 $1.5 \mathrm{~m}$

この外怯凡て Fig. 2 のすのと同じ

次飞坦幅，位相辨別，繼電各部の回路は簡單なりのを 用いているか，更焙很な力式飞改善すれは性能す向上

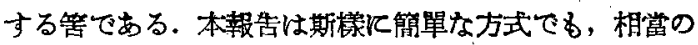

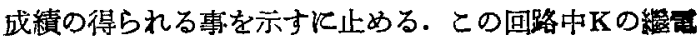
器は特に動作, 開放電流の差の小さいるのが望ましく，

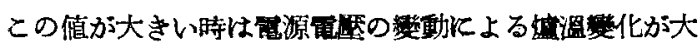
きくなる。

\section{3. 宣 結 果}

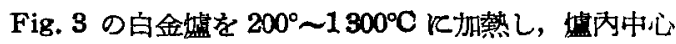
部の温度を $\mathrm{Pt}, \mathrm{Pt}-\mathrm{Rh}$ 熱䍌 $(0.5 \mathrm{~mm} \phi \times 1 \mathrm{~m})$ と內部 抵抗 $800 \Omega の \mathrm{mV}$ メーターとを用いて測定したが，そ

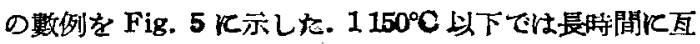
つて恒溫に保たれるが, $1150^{\circ} \mathrm{C}$ 以上では次第に溫度が 下降して來る。その程度は高溫程著しい. 又新しい白金

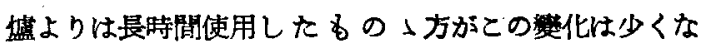
い. この原因は不明であるが白金線に何等かの變質が 起つて抵抗值を高めるものと思われる. 短時閒の場合は $1300^{\circ} \mathrm{C}$ 飞到るまで任意の温度でメーターで請め奴程度

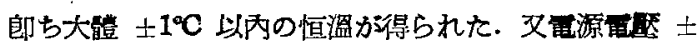

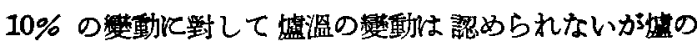
周囯を俱空にすると溫度が低下する，その例は Fig. 6 と示した. 一體このオ式では白金線の全抵抗值をある一 定值に保つ核，加熱電流を加減している譯であるが，白 金線は全部が一樣の溫度になつているのではなく"end cool”のため兩端は墟の中央部より溫度が低い，盾空內 では空氣中より“end cool”可影響が少くなつている 篇高温の部分が長くなる. 全抵抗值が一定となるために は, 高温部分の溫度は空策中にある時に比へて低い值と

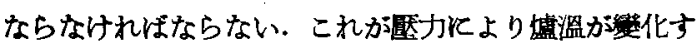

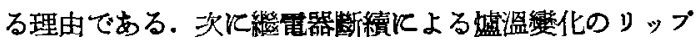

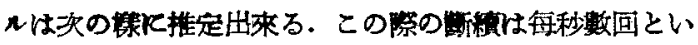

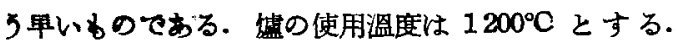

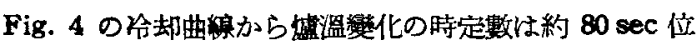

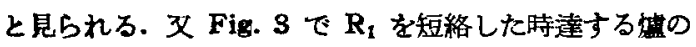

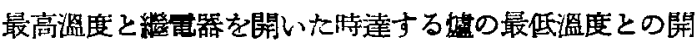

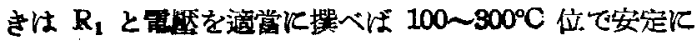

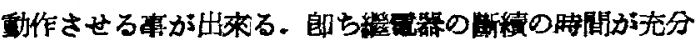

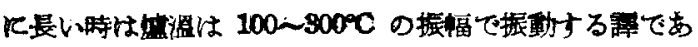

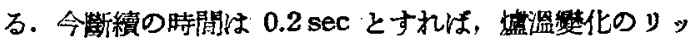
プルは $\left(100 \sim 300^{\circ} \mathrm{C}\right) \times \exp (0.2 / 80)$ 即ち $0.25 \sim 0.75^{\circ} \mathrm{C}$ 位. の甚だ小さい值となる.

大型の電氣嫬にこの方式を應用する事は Fig. 3 の回

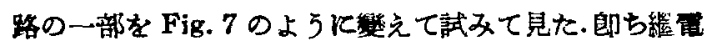

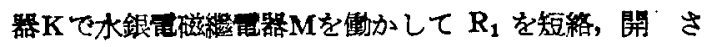

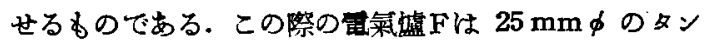
マン管に $0.5 \mathrm{~mm} \phi \mathrm{Pt}$ 線を約 $5 \mathrm{~m}$ 撩き，その上を厚さ $5 \mathrm{~cm}$ 位までアランダム, 石編等で断熱した大體 $500 \mathrm{~W}$

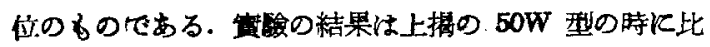
へ隼動時間が長いだけで㱠んぞ同樣な結果が得られた。

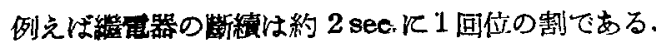

熱容量の大きい場合對しては本法の特長である迅速 な應動といろ事が不必要になることの外，上述のように 高溫度で第飞娍溫が但下する事 $\dot{R}_{\mathbf{1}}, R_{\mathbf{2}}$, での電力損失 が少なくない事等のため良い方法とは云竞ないが，稌り

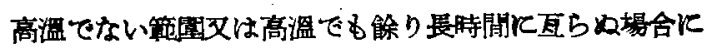
は極めて精密な溫度調篩洗として有效で，珠低温の場

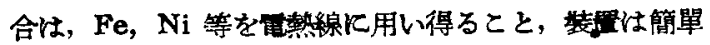
て手等怩作れる等のため便利である.

(昭和 26 年 11 月 5 日受理)

交 献

(1) J. Strong: Procedures in Experimental Physics, Prentice Hall Inc. 524 (1939); American nstitutes of Physics : Temperature, Its Measurement and Control in Science and Industry. Reinhold Pub. Corp. 604

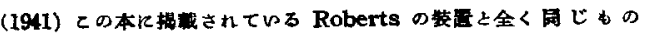

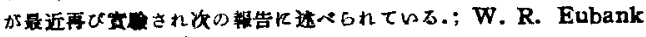
: RSI, 21, 845 (1950)

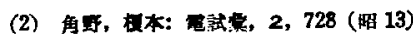

